\title{
UNA VISIÓN ESTRUCTURAL DE LA POLÍTICA EXTERIOR ARGENTINA Y EL ROL DE CHILE DESDE EL PROCESO DE DEMOCRATIZACIÓN DE 1983*
}

\section{A structural view of Argentina's foreign policy and the role of Chile since the democratization process of 1983}

Alejandro Simonoff*

Recibido: 8 de octubre de 2012. Aprobado: 4 de marzo de 2013.

\section{RESUMEN}

El artículo analiza la política exterior argentina de los últimos 30 años y en donde se construyó una estructura triangular entre Washington y Brasilia. El balanceo que realizó la Argentina entre estos dos polos fue producto de las innovaciones ocurridas en el primer gobierno democrático: el giro realista hacia los Estados Unidos y la política de cooperación hacia los vecinos que permitieron buscar márgenes de maniobra en el escenario internacional. Aunque durante la década de 1990 hasta la crisis de 2001, este esquema continuó buscando la vinculación acrítica con la gran potencia y que esto contrapesara el lugar de Brasil, y desatendiendo la búsqueda de márgenes de maniobra. Con posterioridad a la crisis, los lineamientos seguidos en diversos planos que atendieran tanto las demandas internas como externas permitieron, no sin dificultades y contradicciones, volver hacia el sendero de la autonomía. A pesar de estar fuera de esta estructura, Chile cumplió un rol fundamental en esa política exterior en los diversos momentos, como se detalla en el texto.

PALABRAS CLAVE: Política exterior, historia reciente, relaciones internacionales.

* Este artículo es resultado de investigación del Programa de Incentivos a docentes - investigadores de la Administración Nacional proyecto 11/J116 "Análisis de los lineamientos principales de la inserción argentina en el mundo actual, a través de su política exterior, la cooperación regional y la agenda de seguridad".

** Universidad Nacional de La Plata (UNLP), Instituto de Relaciones Internacionales, Instituto de Investigaciones en Humanidades y Ciencias Sociales, La Plata, Argentina. Correo electrónico: asimonoff 2000@yahoo.com.ar. 


\begin{abstract}
The article analyzes Argentina's foreign policy over the last 30 years and how a triangular structure was built between Washington and Brasilia. The balance that Argentina created between these two poles was the result of innovations that occurred during the first democratic government: the realistic shift towards the United States and the policy of cooperation with their neighbors, which allowed them room to maneuver in the international arena. Although during the nineties up to the 2001 crisis, this approach continued to look for an uncritical alliance with the great world power that this counterbalanced the rise of Brazil, and neglected the search for room to maneuver. After the crisis, the new lines of work in various arenas, that could meet both internal and external demands allowed, not without difficulties and contradictions, signaled a return to the path of autonomy. Despite being outside of this structure, Chile played a role in that foreign policy at various times, as detailed in the text.
\end{abstract}

KEYWORDS: Foreign policy, recent history, international relations.

\title{
I. INTRODUCCIÓN
}

El fin de la Segunda Guerra Mundial marcó un nuevo escenario internacional con el desplazamiento definitivo de los europeos y el ascenso de la Unión Soviética y los Estados Unidos que impuso nuevos rumbos en la política exterior argentina.

Los proyectos de incorporación al nuevo escenario internacional estuvieron marcados por una puja entre los esquemas autonomistas -llevados casi siempre por administraciones democráticas- y esquemas de alineamiento hacia los Estados Unidos -llevados a cabo por gobiernos de facto-; son las nuevas políticas exteriores (1946-1983) que se diferenciaron claramente de la fase anterior que giraba en torno a la prioridad británica. E incluso, las pretensiones de alineamiento no fueron acompañadas en gran medida por Estados Unidos, como ocurrió en la Revolución Argentina (1966-1973); y en otras que enfrentaron su agenda global, como en el último gobierno militar (1976-1983).

La falta de continuidad institucional reflejó cambios constantes al ritmo de la sucesión de gobiernos civiles y militares, e incluso en algunos casos dentro de un mismo gobierno. En aquel contexto operaron tanto la polarización política interna (peronismo-antiperonismo), y externa (la cruzada anticomunista y el recelo a las posiciones nacionalistas desde lo económico por parte de Washington) como la económica (cam- 
po-industria), en donde existieron múltiples y cruzadas combinaciones, entre ellas, que condujeron a la incapacidad de definir un rumbo sostenido. Estos constantes cambios llevaron al país a una errática situación internacional que incidió en su pérdida de posición internacional y en las oportunidades que el mundo ofrecía.

La política hacia la región tampoco estuvo exenta de oscilaciones, aquí los gobiernos civiles apostaron a reforzar la estrategia de cooperación hacia los vecinos en general, y particularmente con Brasil, con el intento de crear un nuevo ABC en tiempos de Perón, los Acuerdos de Uruguayana con Frondizi y los de la Cuenca del Plata con Illia, y Chile, así como acuerdos de complementación económica de 1964, son ejemplos de esto.

En cambio, las dictaduras privilegiaron los supuestos geopolíticos en estas relaciones y generaron enfrentamientos con ellos, como la discusión en torno a la construcción de Itaipú con Brasil en la segunda mitad de los 60, o la creciente tensión con Santiago por la cuestión del Canal de Beagle, que casi puso a ambos países al borde de la guerra en 1978.

Otro elemento que le agregó complejidad a la cuestión es que la evaluación del proceso de inserción fue controvertida, mientras en Puig y sus sucesores ${ }^{1}$ las decisiones autonómicas fueron ponderadas como positivas (Puig 1988), los occidentalistas ${ }^{2}$ las calificaron de aislacionistas, Carlos Escudé, como heredero de este último sector, las evaluó como “desafíos" con costos, e incluso como "victorias pírricas" (Cisneros y Escudé 1998:17).

Russell y Tokatlian fueron más sensibles a esta apreciación, como se observó en su "paradigma globalista". ${ }^{3}$ No resultó casual que el primer elemento de dicho paradigma

1 Ellos conformaban los llamados latinoamericanistas o autonomistas, quienes analizaron las asimetrías existentes en la relación entre América Latina y Estados Unidos, los efectos negativos de ellas, pero también de los márgenes de maniobra que permitirían la consecución de los objetivos nacionales por parte del Estado-nación, siendo este, su variable de análisis. La ideología que lo sustentó fue de tipo nacionalista y mercadointernista, asimilable a los populismos existentes en esta época. Y percibió a la integración como la expansión de su modelo económico orientado a favorecer la autonomía. Esta última fue percibida como el desarrollo del interés nacional, objetivado por un uso racional y no por deseos y pasiones (Simonoff 2012).

2 Este sector que propiciaba un alineamiento con Estados Unidos y su enfrentamiento con el tercermundismo o latinoamericanismo, en el que se inscribía Puig y su escuela (Figari 1985:24), ya que percibieron estas acciones autonómicas como aislacionistas. El aporte de este grupo no fue significativo desde el punto de vista teórico, muchos de sus trabajos terminaron siendo "tendenciosos" y con un juicio crítico no fundamentado "en fuentes primarias o secundarias relevantes.” (Rapoport 1990:556).

3 Estos autores encuentran a partir del fin de la Segunda Guerra Mundial, una nueva realidad externa e interna signada por las polaridades Este-Oeste, Norte-Sur, y la necesidad del país de poner en marcha una nueva estrategia de desarrollo configuraron un nuevo modelo de inserción internacional que denominaron globalista. En el 
fuese el no alineamiento con Estados Unidos, si bien esto fue reconocible en algunos gobiernos del período, no fue aplicable para todos; lo mismo pudo sostenerse con el resto de los elementos aportados (2002:414).

\section{LAS POLÍTICAS EXTERIORES DE LA DEMOCRACIA}

La guerra de las Malvinas fue el punto terminal de esta crisis de inserción del país que puso de manifiesto su debilidad, la equivocada imagen que se tenía de él y del mundo; como así también significó el alejamiento del poder de los militares y tras él, la posibilidad de conjugar un sistema político estable. ${ }^{4}$

Desde la instauración de la democracia en la Argentina, los objetivos estuvieron concentrados en la reinserción en el mundo que marcaron la nueva agenda. ${ }^{5}$

La llegada de la democracia también fue un punto de inflexión para la disciplina, el concepto de autonomía que había resultado articulador de un primer momento paradigmático, y que se expresaba en la confrontación entre autonomistas y occidentalistas de los años 60 y 70, dejó su lugar a la aparición de un escenario más complejo.

A partir de aquí se constituyeron al menos cuatro conceptualizaciones teóricas distintas, tres desde un análisis eminentemente político y otra, con una prevalencia de lo socioeconómico. Dentro de las primeras encontramos a la puigiana o autonómica clásica, la escudeana o neoconservadora, otra de inspiración neoliberal o relacionalista, y la última expresada por Mario Rapoport y Raúl Bernal Meza, entre otros.

eje Este- Oeste, Argentina se definió como un país occidental. Aunque todos los gobiernos procuraron mantener cierto margen de decisión propia, la creciente dependencia económica del país en referencia a EE UU atenuó en ocasiones este perfil autonomista; mas acosados por la conveniencia que por convicción, los gobiernos argentinos se mostraron menos dispuestos a confrontar con la potencia del norte, a diferencia del período anterior. En el ámbito sur-sur, Argentina dio prioridad a los vínculos horizontales con sus vecinos, aunque no logró establecer un patrón de relaciones duradero. En una primera fase la visión de Brasil, principal referente de la región, estuvo signada más en la competencia que en la cooperación. Sin embargo, llegando al final de este período, la inclusión de la democracia como un aspecto de la política exterior en el gobierno de Alfonsín, permitió abrir un nuevo capítulo de relaciones con la región, y en particular con Brasil, en donde la visión cooperativa con el país vecino se mostró claramente predominante (Russell y Tokatlian 2002).

4 Este último dato, la estabilidad institucional, aportó un rasgo de previsibilidad de estas políticas, cosa que tampoco fue desdeñable si tenemos en cuenta la historia argentina desde 1930.

5 Para Roberto Russell, la idea de la "reinserción internacional" es un "mito" que "necesitó desde un tiempo más lejano la noción de aislamiento para sostenerse como rasgo secular" (2010:296). 
La interpretación neoconservadora, próxima a las lecturas occidentalistas, encontró en la oleada neoliberal y neoconservadora del fin de la Guerra Fría un impulso singular. Mientras el modelo clásico vio en el sistema internacional las asimetrías, este se sustentó en la aceptación del orden político (de características unipolares), económico y financiero internacional (marcados por la globalización). Su ideología navegó entre el neoconservadurismo político y el neoliberalismo económico. La agenda política con las grandes potencias está marcada por el programa neoconservador en materia de seguridad (donde los países periféricos no deben poseer tecnologías sensitivas) y en lo económico se concentró en el rol que las fuerzas del mercado internacional le otorgaron al país y el rol de la integración regional estuvo en función de la apertura económica. El interés nacional fue definido solo en términos económicos, haciendo de la autonomía, a través de un proceso de disección conceptual en consumo e inversión, un elemento cuyo uso fue diferido permanentemente hacia el futuro, hasta hacerlo desaparecer como práctica (Simonoff 2003:136-42).

La corriente que denominamos neoliberal está formada principalmente por Roberto Russell y Juan Gabriel Tokatlian, sus influencias estuvieron vinculadas al constructivismo de Alexander Wendt (idealismo estructural) y para los análisis de alianzas regionales a Kenneth Waltz (realismo estructural) y a Stephen Walt (origen de las alianzas) (Russell y Tokatlian 2002:405).

La escuela socio-histórica estuvo definida por entender el análisis de la política exterior no solo en términos políticos, sino que estos no podían desentenderse de la "influencia decisiva" de los modelos de acumulación "en la evolución del Estado, los regímenes políticos y en la formación de la política exterior" (Rapoport y Spiguel 2003:170-71).

Se presentó como un "un abordaje multidimensional y complejo, es decir, de una 'historia social'..." Para la construcción de esta opción fue importante la convergencia con la Escuela de Brasilia, conducida por Amado Cervo. A diferencia de las otras escuelas siguientes, esta se propone "una mirada propia" de la disciplina, fuera de la influencia anglosajona. Esta perspectiva posee dos características: una, metodológicas, inspirada en la obra de Jean-Baptiste Duroselle y otra, su enfoque histórico-estructural, del sistema mundo de Emmanuel Wallerstein (Bernal Meza 2005:350-51). 


\section{La política exterior del gobierno de Raúl Alfonsín (1983-1989)}

La idea de que un nuevo régimen democrático impuso una nueva política exterior resultó controvertida, salvo en los sectores autonomistas, los cuales rescataron el cambio de forma de gobierno con la llegada de una estrategia autonomista, heterodoxa, "expresada en forma coherente", como lo destacó en su momento Juan Carlos Puig (1988:45), el resto observó continuidad con la dictadura, o más generalmente con el resto de las políticas exteriores de la Guerra Fría.

Cierto fue que estos sectores críticos también apuntaron a los cambios que la búsqueda de márgenes de maniobra poseía en el escenario del fin de la Guerra Fría, sobre todo a partir del llamado "giro realista" de mediados de los $80 .{ }^{6}$

Para la de inspiración neoliberal, el giro le permitió definir a esta fase como una transición entre dos ciclos fuertes, uno largo (el de la Guerra Fría, o también llamado paradigma globalista) y otro corto (el de los 90, o de "la victoria temporaria del paradigma liberal") (Russell 2010), aquí no se vio ese hecho como un ajuste, como en el caso de la escuela puigiana, sino como un cambio.

Podemos agregar además que la lectura de Russell hizo hincapié en que la política exterior de Alfonsín se construyó sobre la necesidad de fortalecer la democracia (2010), y que el análisis de Rapoport incluyó otro elemento: la búsqueda de instrumentos para salir de la crisis económica a los cuales criticó por su orientación, cada vez menos heterodoxa y más ortodoxa (2009).

El debate se concentró en la forma de encarar una relación con Washington, menos confrontacional y más cooperativa que en la etapa anterior. Mientras para los herederos del autonomismo, como Figari, existió desde 1983 una continuidad en la elección temática, la relación con Washington se basó en la "reactualización del principio de no intervención a través de negociaciones maduras y moderadas con Estados Unidos" (Figari 1993:220) que le permitieron a Alfonsín llevar a cabo "una política de autonomía ingenua", aunque esta actitud "no constituyó ningún inconveniente para que reconociera una realidad insoslayable no comprendida en el pasado: con los Estados Unidos debían existir relaciones maduras" (Figari 1997:130).

6 Se llamó así a la rejerarquización de la política hacia Estados Unidos, dado el peso de las cuestiones económicas, que hicieron que esta relación tuviese una relevancia mayor al diseño original. Como señala Figari, en los primeros años de Alfonsín se produce una síntesis entre las tesis occidentalistas y latinoamericanistas, que pujaban por determinar los lineamientos de nuestra relación con el mundo en los 60 y los 70 (1997:21). 
Para los continuadores de la tradición occidentalista, como Escudé, el corte no se produjo en 1983, ni en 1985, sino con la política de Menem que representó "un giro brusco respecto de la política del gobierno de Alfonsín y un viraje de 180 grados de la política altamente confrontacionista de la dictadura militar." Las diferencias que encontró estuvieron en las políticas de Alfonsín y su equipo que "condujeron siempre a la confrontación con los poderosos" y que habría generado costos. Las de Menem, Cavallo y Di Tella partieron "de la aceptación realista del liderazgo de los Estados Unidos" y por lo tanto "no tienen costos y pueden eventualmente, generar beneficios significativos" (Escudé 1992:36-8).

Resultó claro que Escudé impugnó la existencia del giro realista, ya que la valoración de este concepto fue central para la caracterización de la política exterior radical, como parte de la Argentina subordinada, ${ }^{7}$ y escondió el verdadero objetivo de su crítica, la estrategia multilateral y de carácter autonomista, frente a un alineamiento con Washington. ${ }^{8}$

Empero no existió discusión sobre el cambio de la política exterior iniciada en 1983. Fue en la relación con los vecinos, fundamentalmente Brasil y Chile, que los sectores neoliberales no dudaron en calificarla como "notoria" (Russell 2010:268), como así también sus acérrimos críticos neoconservadores que lo evaluaron como un corte con el pasado (Cisneros 1998:73-6).

En el caso de la relación con Brasil, el fracaso del Consenso de Cartagena para el tratamiento de la deuda externa permitió el paso a un proceso de integración selectiva. Esta integración con Brasil tuvo su origen en los tratados firmados por Sarney y Alfonsín. La firma del acuerdo de 1985 marcó el definitivo alejamiento del aislamiento regional y la búsqueda de una estrategia para enfrentar los desafíos de la creciente integración económica mundial.

En relación al país transandino, había que desactivar los conflictos limítrofes pendientes para pasar a una fase más cooperativa. El Tratado de Paz y Amistad con Chile

7 Para Escudé, la "Argentina subordinada” fue una etapa histórica marcada por el ascenso de Estados Unidos al poder mundial. El nuevo esquema de inserción internacional estuvo determinado por la confrontación de nuestro país con Washington y en donde, producto de esto, la Argentina ingresó en un período de declinación (Cisneros y Escude 1998).

8 Los detractores realistas lo que buscaban no era "una relación madura y equilibrada", sino que "lo aconsejable era repetir la fórmula" con Estados Unidos como lo había sido con Gran Bretaña a fines del siglo pasado y principios del actual." (Paradiso 1993:195). 
ratificó la propuesta del papa Juan Pablo II no sin ciertas resistencias. ${ }^{9}$ El canciller Dante Caputo consideró que: "el proceso de negociación que culminó con el Tratado de Paz y Amistad, significó establecer un límite cierto y definitivo en la zona de litigio, pero además significó un triunfo de la racionalidad y de la sensatez" (Caputo 1986:4). En ese mismo sentido apuntó Oscar Fuentes Lazo, al señalar que el Acuerdo reflejó "la voluntad de gente sensata de jugarse por la paz y dar la espalada a los que invitaban a aventuras fratricidas" (2007:52).

Si bien Chile ganó la soberanía de las islas en disputa, el nuevo tratado supuso no solo un nuevo paradigma para la resolución de los conflictos pendientes, aspecto reclamado por la Argentina desde los años 50 del siglo XX, sino también abrió las posibilidades de concertar una política más cooperativa.

Pero además la firma tuvo dos efectos para la política radical: uno interno y otro externo. El primero para la administración de Alfonsín, "la solución de la disputa fronteriza estaba indisolublemente ligada a la viabilidad de la consolidación democrática en la Argentina y el desplazamiento de los sectores autoritarios" (Rodríguez 2011:122). Y externamente, si bien se tenían relaciones "cordiales" con el régimen chileno, se "rechazaba la posibilidad de una integración más profunda" (Rodríguez 2011:122-23). A pesar de la persistencia de la dictadura pinochetista, como lo señaló Pablo Lacoste, "lentamente quedaban atrás las tensiones diplomáticas y militares, para dar paso a un ciclo completamente nuevo" de asociación y cooperación que continuó y se profundizó con Menem (2004:75). Pero además existía otro objetivo adicional: colaborar con la oposición a fin de aportar al proceso de democratización chilena (Rodríguez 2011:153).

Con respecto a las Malvinas, el gobierno radical conformó una respuesta multilateral e institucionalista, llevando su reclamo a los foros internacionales para demandar la discusión por soberanía frente al Reino Unido, ante el fallido intento de acercamiento bilateral en Berna (1984), mientras por otro lado buscó en los polos de poder internacional cambiar la situación de posguerra, a través de la mediación norteamericana para el restablecimiento de relaciones y los acuerdos pesqueros con la Unión de Repúblicas Socialistas Soviéticas (URSS).

9 Un dato curioso fue que durante la dictadura, los partidos políticos nucleados en la Multipartidaria habían aceptado esta propuesta; sin embargo, una vez llegado el radicalismo al gobierno, el justicialismo se alejó de ella y obligó a la administración de Alfonsín a que realizara un plebiscito no vinculante (en el cual votó casi 74 por ciento del padrón electoral y positivamente 78 por ciento contra 22 por ciento), con el fin de presionar al Senado, con mayoría peronista, y poder aprobarlo en el Parlamento. 
Como ya lo hemos señalado, todos los autores hablan de limitaciones en las políticas autonómicas de Alfonsín, pero salvo los casos de la escuela puigiana, este cuestionamiento tuvo y tiene un doble filo: no apuntaron solo a las estrategias, sino también, y sobre todo, a esa teoría.

\section{La política exterior de Carlos Menem (1989-1999)}

Durante el gobierno de Carlos Menem, las interpretaciones se concentraron con diversas valoraciones, en sus características de novedad. Aquí la lectura neoconservadora logró imponer uno de los anhelos de los occidentalistas: que la autonomía era sinónimo de aislamiento y confrontación.

Aunque no queda muy claro cuáles fueron las condiciones de ese aislamiento expuesto por Ferrari, ya que cuando lo describió, lo hizo como una cuestión geográfica de la Argentina agroexportadora y no por su naturaleza política, como habría emergido en la segunda mitad del siglo XX (1979:9-12).

El dato fue que el realismo periférico, ante las evidentes inconsistencias del concepto de aislamiento como crítica a los efectos de la autonomía, lo reemplazó por el de confrontación inútil. Fue precisamente su abandono, junto con la adscripción a un régimen democrático y la economía de mercado, lo que constituyó, según esta lectura, una nueva fase histórica: la "Argentina postmoderna" (1989-2001) (Cisneros y Escudé 1998:18-9).

Podemos inferir que las estrategias que confrontaban en algún plano con Washington fueron consideradas como desafíos a un alineamiento automático, cuando en realidad fue lógico que los países disputasen entre sí, ya que representan intereses diversos; la cuestión está en el grado de esa confrontación, o como señaló Juan Carlos Puig, cuando los intereses de la potencia dejan de ser cotidianos para ser vitales (1980:153).

Los neoliberales adoptaron también estas críticas, cuando afirmaron que ya no importaba quién gobernara, pues el camino a seguir con respecto a Estados Unidos sería el mismo (Russell 1994). 
Luego pasaron a tipificar ese tiempo como de "aquiescencia pragmática" que se distinguió de las políticas exteriores anteriores, el llamado "paradigma globalista", como de las posteriores (Russell y Tokatlian 2003). ${ }^{10}$

En el caso de la escuela puigiana y la sociohistórica sus análisis fueron marginados, sobre todo por el acento puesto en las asimetrías, cosa que el discurso del nuevo orden internacional relegó y que llevó a un acercamiento importante entre ellas.

En el diseño del gobierno de Menem, la vinculación con Washington buscó, además de generar una "subordinación autoimpuesta", según la feliz expresión de José Paradiso (1993:200), resolver la puja por el liderazgo sudamericano con Brasil a favor de Argentina. Un momento interesante fue la fuerte apuesta, a través de este alineamiento y la participación en las fuerzas de paz de Naciones Unidas para potenciar a la Argentina como referente regional, además de la incorporación del país como aliado extra OTAN. Pero este esquema se confrontó con otras iniciativas como las diversas propuestas de reforma al Consejo de Seguridad, donde Brasil buscó ocupar un sillón permanente en dicho organismo, generando tensiones con nuestro país.

El Mercosur, como acuerdo de unión aduanera y mercado común principalmente, a diferencia de los de 1985, estuvo influido por la ideología neoliberal de los suscriptores, ya que fue pensado como un instrumento comercialista para sumarse a la globalización, más que como uno alternativo a esta. La falta de coordinación de estrategias de inserción no alejó las tensiones entre sus miembros, por la falta de adecuación de políticas exteriores y económicas comunes, y por la prioridad otorgada a la relación con Estados Unidos por Argentina, frente a cierto alejamiento de Brasil de este.

Pero estas dificultades no impidieron que ganase en importancia como instrumento para la negociación con otros espacios regionales como el Área de Libre Comercio de las Américas -bajo la fórmula "cuatro más uno"-, o el acercamiento con la Unión Europea -con la cual se afirmó la voluntad de crear una asociación interregional-, o con

10 El modelo de "aquiescencia pragmática" fue definido por Russell y Tokatlian, como aquél que se inició en los años 90 del siglo XX hasta diciembre de 2001. La aquiescencia es un tipo de conducta que se caracteriza por la conformidad autoimpuesta por parte del Estado, cuando ante la falta de alternativas realistas se adopta una política exterior subordinada a un actor externo. En este período el interés nacional fue definido en términos de desarrollo económico y en consecuencia el modelo de inserción seguido por el gobierno de Argentina, tuvo a Brasil y a Estados Unidos como principales protagonistas: Brasil fue visto instrumentalmente como una contraparte funcional en términos económicos y disfuncional en términos políticos, dado que el vínculo estaba subordinado a la relación con Washington; mientras que Estados Unidos fue racionalizado como el referente del "alineamiento estratégico", siendo la piedra angular de la política exterior argentina (Russell y Tokatlian 2002). 
posterioridad a la crisis de 2001 cuando se institucionalizaron misiones conjuntas con el sello comunitario.

Para Chile en esta fase existió un plano de una mayor cooperación, ya que el proceso de apertura y liberalización iniciado en Buenos Aires permitió una mayor convergencia de sus economías, y en Argentina, producto de la privatización y la convertibilidad, transformó su estructura productiva convirtiéndose en exportador de energía (debido a la explotación irracional de los recursos naturales y la caída de la producción industrial).

La mayor complementación de los modelos económicos no impidió la existencia de cierta puja con Chile ante la integración a la economía norteamericana, ante la ambigüedad que el gobierno de Menem tuvo en la materia, y como pudo observarse en las discusiones del Grupo Río de 1997.

También en este plano, el fin de la dictadura de Pinochet en 1990 y la posterior incorporación de Chile al Mercosur político en 1996, reforzaron la faz cooperativa entre ambos Estados. Fue lo que Lorenzini denominó la superación de los obstáculos de la "vieja política" a la "nueva política" (2011:183).

Pero la subsistencia de la "vieja política" estuvo concentrada en los problemas de límites y por ello se firmó un primer acuerdo con el presidente Patricio Aylwin para solucionar los 24 puntos en disputa, dejando de lado el conflicto de Laguna del Desierto y el de Hielos Continentales, según lo establecido en el Tratado de Paz y Amistad de 1984.

El primero fue llevado a un arbitraje internacional que falló en favor de las pretensiones argentinas y en el segundo se intentó una solución política a través de la demarcación de una poligonal consistente en fijar una línea equidistante entre las pretensiones de ambos países.

A fines de 1996, el presidente de Chile, Eduardo Frei, y su par argentino, Carlos Menem, al no encontrar ninguno de los dos gobiernos acuerdo por parte de sus parlamentos, avanzaron en uno nuevo que estipuló la conformación de una comisión interparlamentaria que analizó la debatida "poligonal". En 1998 emitió un dictamen que fue acordado por ambos congresos, y fue aprobado al año siguiente, en donde el 70 por ciento de los reclamos argentinos fueron considerados (Simonoff 1999). 
El cierre de las disputas fronterizas con Chile marcó la apertura hacia una agenda económica entre los dos países y aprovechamientos de recursos en común, como asimismo el encuentro de una salida al Pacífico para el Mercosur.

Durante las Presidencias de Menem, con respecto a Malvinas trató el tema en sintonía con los deseos de los poderosos, y estableciendo dos planos: uno bilateral, con los británicos en el cual se buscó allanar sus intereses económicos y políticos, e implementando una peligrosa estrategia llamada de "seducción" hacia los isleños. ${ }^{11}$

\section{La política exterior de Fernando de la Rúa (1999-2001)}

La gestión de Fernando de la Rúa fue ubicada en el marco de una continuidad de la gestión de Menem, aunque existieron ciertos elementos diferenciales, estos no llegaron a plasmarse en una política diferente. Evidentemente la atadura a la convertibilidad resultó el principal impedimento para realizar cambios en la estrategia de inserción aliancista.

Las vinculaciones entre el modelo económico de la convertibilidad y el de inserción internacional del "realismo periférico", los vuelven inescindibles, no existiendo posibilidad para que cada uno fuese utilizado independientemente del otro.

Durante esta administración se continuó pensando en conciliar la prioridad Mercosur con la política hacia Chile, postulando su incorporación al bloque regional, además se buscaron coincidencias con respecto al Tratado Antártico -al margen de los conflictos existentes entre los dos países-, y para que Buenos Aires sea la sede del mismo (Simonoff 2007).

Esta ampliación del Mercosur buscó evitar la presencia gravitatoria de Brasil, pero terminó fracasando cuando, a fines de 2000, la nación trasandina decidió integrarse al Tratado de Libre Comercio con Estados Unidos.

De hecho sectores del gobierno, fundamentalmente su último ministro de Economía, Domingo Cavallo, recomendaba salirse del Mercosur e "iniciar conversaciones para

11 La Argentina considera a los kelpers como población implantada y por lo tanto su reclamo de autodeterminación sería consagrar el colonialismo, más que terminar con él. La estrategia de seducción llevada adelante por la administración menemista puso en riesgo este principio sostenido por Argentina y contenido por la Resolución $\mathrm{N}^{\circ} 2.065$ de la Asamblea General de Naciones Unidas. 
incorporarse [al NAFTA], siguiendo el modelo de negociación que lleve adelante Chile" (Cavallo 2001:264-65).

Los gobiernos posteriores a Menem buscaron un alejamiento de la estrategia de seducción. A pesar de las diversas estrategias de inserción internacional en general, y con respecto a Malvinas en particular, en los años posteriores a Menem encontramos cierta continuidad, o lo que más ampulosamente se llama "Políticas de Estado".

La continuidad de la convertibilidad, que afectaba la competitividad de la economía argentina y repercutió en vastos sectores de la sociedad, llevó los índices de pobreza a términos nunca vistos, que se tradujeron en una pérdida de legitimidad del gobierno, el cual colapsó, y tras una serie de sucesores, finalmente Eduardo Duhalde quedó a cargo del Ejecutivo.

\section{Las políticas exteriores tras la crisis de 2001}

Las lecturas de la crisis de 2001 en el sentido de un corte con el pasado fue mayoritario, pero lo cierto fue que sus sentidos no fueron los mismos. Mientras para Rapoport, el alejamiento de la convertibilidad resultó central para una nueva política exterior, que terminó expresándose en la gestión de Néstor Kirchner (2009), los autonomistas marcaron la valoración de la búsqueda de márgenes de maniobra (Figari 2004), frente al modelo anterior que privilegió la inserción, más erráticas resultaron las lecturas neoliberales y neoconservadoras.

La lectura de Russell (2010) consideró la reaparición de elementos del segundo núcleo, o modelo globalista, y el desplazamiento de los del tercero, en una idea un tanto positivista de la evolución de las cuestiones políticas, lo que condicionó su visión de este período como de otros.

La lectura de Escudé que pasó de determinar primero la del Estado parasitario, categoría en la cual la política exterior "se convierte en un instrumento" de la política interna y por lo cual:

es improbable que el futuro depare políticas exteriores "racionales", pensadas en función de los intereses de largo plazo en un contrato social democrático. Por lo menos hasta que la condición de parásito sea superada, no volverán a implementarse políticas 
exteriores como las de Menem y Alfonsín que más allá de sus aciertos o errores, fueron por momento admirables en su disposición al sacrificio electoral... (Escudé 2005:117)

Pero no solo el cambio de la situación interna afectaba el análisis escudeano. También el alejamiento del horizonte de un mundo unipolar que lo llevó a sostener que en los últimos años producto del "caos sistémico", se "han reducido los costos de las confrontaciones con la potencia hegemónica" que tuvo como consecuencia que las "ecuaciones del 'realismo periférico' se ha(ya)n transformado" (Escudé 2004:199).

Es extraño que en un artículo reciente, y ante el surgimiento de China como una de las principales potencias mundiales, continuó planteando los mismos condicionantes que para los escenarios anteriores, a pesar del cambio de las "ecuaciones" (Escudé 2011).

Esta transformación de las ecuaciones del realismo periférico lo llevaron a una revisión del proceso, al considerar que las políticas exteriores de las administraciones kirchneristas son una expresión de realismo periférico blando, frente a una supuesta aplicación ortodoxa de su teoría en los 90 (Escudé 2009).

En cierto sentido existen puntos de continuidad de algunas políticas iniciadas en los 90, y reclamadas por Escudé, como la firma del Tratado de no Proliferación de Armas Nucleares (TNP), de Tlatelolco, por ejemplo, pero nos preguntamos: ¿son suficientes para establecer la vigencia del realismo periférico, o estamos claramente en otra instancia teórica y de la práctica de la política exterior?

Como ha sostenido Mario Rapoport, con la llegada de Néstor Kirchner estaríamos viviendo un nuevo modelo de política exterior sustentado en la reindustrialización, desendeudamiento y desarrollo económico "que todavía estamos transitando" (2009:26), claramente distinto al de la anterior década. Aunque no nos deja de ser extraño que ambos autores, dos de los principales polemistas de la disciplina desde los años 80 , hoy coincidan en su evaluación sobre la administración kirchnerista.

Frente a las estrategias adoptadas por los sucesivos gobiernos desde 2001 no podríamos suponer la existencia de una continuidad ante el cambio de modelo económico y de inserción que obedeció a la propia supervivencia del Estado-nación y de la sociedad argentina.

En función de la importancia que para Argentina tienen Brasil y Estados Unidos, se fueron constituyendo ejes como la securitización de la agenda mundial, los vínculos 
con la región y el Mercosur, la negociación de la deuda externa, la reinserción internacional del país y la crisis financiera internacional de 2008.

La securitización de la agenda internacional llevó a los gobiernos argentinos en medio de la crisis a evitar compromisos directos con la política de Washington, aspirando a mecanismos de carácter multilateral, como mantener y reforzar las misiones de paz, buscar ciertos linkages con la lucha contra el terrorismo, como el avance judicial sobre ciudadanos iraníes en la causa de los atentados en los años 90, pero fijando distancia del unipolarismo.

Existieron coincidencias con Chile en torno a la intervención norteamericana en Irak, aunque como señaló María Elena Lorenzini, "esto fue una simple coincidencia, puesto que no tuvo lugar un proceso previo de concertación y coordinación de política" (2011:177).

Volviendo a la Argentina, debemos señalar que la llegada de los demócratas permitió observar cierto agotamiento de la estrategia multilateral y la necesidad de un replanteo de la misma que aún no lo vemos aparecer con claridad.

El marco externo trajo aparejados desafíos que sumados a la crisis de 2001, hicieron que Argentina profundizase su rol regional. Tras ciertos titubeos iniciales, la estrategia de inserción internacional tuvo un vuelco hacia la opción de Brasil, y un tratamiento razonable hacia la gran potencia del norte del continente.

El impacto sobre la región redundó en una mayor autonomía en muchos aspectos, pero también trajo aparejadas nuevas responsabilidades, como lo demostró la intervención en la Misión de Estabilización de las Naciones Unidas en Haití MINUSTAH y en las diversas crisis políticas que tuvieron lugar principalmente en el Cono Sur.

En este plano, y dentro del marco de la regionalización de las Operaciones de Mantenimiento de la Paz (OMP) fueron, tras Afganistán e Irak, o formas de compensación en contra de la legalización de la segunda, como podría ser el caso de Chile, o la forma de aporte indirecto de tropas, como puede ser el de Argentina, lo cierto que fue un ámbito de convergencia y que puede convertirse en una oportunidad para un comportamiento autonómico.

En este esquema debemos sumar a Brasil, que no quedó reducido al envío de tropas, sino que también a la articulación de políticas para cumplimentar el tipo de mandato 
de la operación entre los tres países en el "ABC sobre Haitî", lo que fue un dato por demás auspicioso.

Otro dato para nada menor fue el avance en el plano de la integración de tropas para este tipo de misiones entre Argentina y Chile, los que en el marco de la reunión bilateral conocida como "el $2+2$ " (formado por los cancilleres de Argentina y Chile, Jorge Taiana y Alejandro Foxley, y los respectivos ministros de Defensa, Nilda Garré y Vivianne Blanlot), en diciembre de 2006, anunciaron la puesta en funcionamiento de una fuerza binacional de paz combinada conocida como Cruz del Sur que:

Se trata de la primera experiencia de integración entre fuerzas armadas que, en este caso, tendrá por cometido la conformación de una fuerza militar disponible para misiones internacionales de paz de las Naciones Unidas. La fuerza Cruz del Sur actuará bajo mandato de la ONU y conforme a los parámetros y procedimientos del Sistema UNSAS (United Nations Stand-by Arragement System)" (Simonoff et al. 2007).

Además, está la función de estabilizador regional que se había desarrollado conjuntamente con Brasilia, como por ejemplo en los casos de crisis políticas en Bolivia y Ecuador; tras la creación de la Unasur, estas se realizaron en un marco más institucionalizado y también más limitado al espacio sudamericano que al latinoamericano.

Fue muy interesante en este nuevo plano la reunión entre las presidentas Michelle Bachelet y Cristina Fernández con motivo de la crisis que aquejó a Bolivia, en septiembre de 2008, previa a la reunión de la Unión de Naciones Sudamericanas (Unasur), para coordinar el rechazo a los sectores separatistas.

El eje de la integración regional tuvo al Mercosur como actor central. Este profundizó su perfil como mercado común al sancionar su Código Aduanero en 2011 y establecer como meta final del proceso el año 2019. Pero no fue menos cierto que su principal desempeño fue como instrumento de inserción económica internacional para sus miembros (misiones comerciales conjuntas, participación en el G22 de la Organización Mundial de Comercio, OMC, el rechazo al Área de Libre Comercio de las Américas, ALCA, entre otros).

En el marco de la integración con Chile, en octubre de 2009, ambas presidentas suscribieron el Tratado de Maipú de Integración y Cooperación, el cual para el entonces canciller argentino, Jorge Taiana, constituye "el nuevo marco programático en el cual se 
desarrollará la dinámica de la relación bilateral en las próximas generaciones") (Simonoff et al. 2010).

En el plano de la integración física, a los pasos abiertos en la década de los 90, como el de Jama o Cardenal Samoré, por ejemplo, se le sumaron la conformación de entidades binacionales para la construcción del Túnel Internacional en el Paso de Agua Negra y el Tren Trasandino Central previstos en el Tratado de Maipú.

Pero obviamente que no podemos desatender en el marco de la estrategia de integración las relaciones con Brasil. Estas pasaron de un buen momento, marcado por la solidaridad de ese país en la crisis de 2001, y reforzado con la llegada de Lula da Silva, hasta que a fines del 2004 empezaron a mostrar ciertas tensiones, como lo fueron las discusiones en torno al rediseño del Consejo de Seguridad y el rechazo inicial a la Comunidad Sudamericana de Naciones. Sin embargo, sobre el final de la gestión de Néstor Kirchner estos aspectos parecían olvidados.

A diferencia de lo ocurrido en esa administración, la agenda con Brasilia de Cristina Fernández estuvo marcada principalmente por los efectos de la crisis de 2008. La variante carioca permitió mejorar los términos de negociación internacional, tanto en la integración regional como en las negociaciones en el marco de la Organización Mundial de Comercio.

La relación con Brasil fue menos efectiva en la relación con los organismos multilaterales de crédito, y en este plano Argentina dependió primero de la ayuda de Washington desde la segunda fase de la administración duhaldista, en mayo de 2002, (en la consecución de este apoyo los gobiernos de Ricardo Lagos y Vicente Fox resultaron centrales), y a pesar del compromiso de establecer una estrategia conjunta en la Declaración de Copacabana (2004), y luego, entre 2005 y 2007, dependió del aporte venezolano.

Precisamente, la estrategia de desendeudamiento ha sido exitosa, ya que virtualmente Argentina salió del default declarado a fines de 2001. Se sustentó en dividir a los deudores en dos tipos: los tenedores privados, quienes tras dos fases de reestructuración con una importante reducción en 2005 y 2010, sumaron un 92 por ciento del total, y los institucionales, con los cuales se avanzó en una esquema de negociación de costos recíprocos, a partir de mayo de 2002, y que en 2005 terminó con la cancelación de las acreencias con el Fondo Monetario Internacional. ${ }^{12}$

12 Para los datos sobre el desendeudamiento, véase:

http://www.mecon.gov.ar/finanzas/sfinan/documentos/informe_deuda_publica_31-12-11.pdf 
Restan aun unos 7.000 millones de dólares en manos de fondos buitres, que intentaron a lo largo de todo el proceso obstaculizarlo, y frente a las acreencias con el Club de París que dilató la esperanza del gobierno de mejorar las notas de las calificadoras de riesgo y el retorno de la inversión para permitir la continuidad del crecimiento a tasas "chinas".

Desde el fin de la convertibilidad, Argentina se fue alejando del paradigma económico neoliberal por otro más heterodoxo. Algunos lo denominan neodesarrollista, ya que gracias a un tipo de cambio competitivo, la utilización de la capacidad ociosa y los precios de los commodities se pudo entrar en una fase de crecimiento económico.

La falta de acceso a los mercados internacionales, producto del default, fue suplida tanto por la recuperación de las instalaciones industriales como por el doble superávit en materia fiscal y con los intercambios comerciales con el mundo.

En este último plano se produjo un crecimiento asombroso, ya que se pasó de 34.600 millones de dólares en 2002 a 157.000 en 2011, con un saldo ampliamente positivo que supera holgadamente los 10.000 millones anuales. La única retracción de este crecimiento se observó en 2009 y 2010, en que los intercambios cayeron levemente, pero ampliando el saldo a unos 16.000 en el 2009, por ejemplo. ${ }^{13}$

Fue evidente la profundización y diversificación de destinos de las exportaciones. Las principales áreas de comercialización fueron el Mercosur, que osciló entre 20 y 25 por ciento, mientras que las otras zonas importantes (Sudeste asiático, NAFTA y Unión Europea) rondaron entre 12 y 20 por ciento. Asimismo, las importaciones están menos equilibradas, con una preeminencia del Mercosur, aproximadamente un tercio del total, y el creciente aumento de llegada de productos de origen chino.

En el caso de Chile, la participación en las exportaciones mostró un signo decreciente en esas fechas, ya que en 2002 rondó 12 por ciento y el último año en 6 por ciento, en el caso de las importaciones se mantuvieron constantes en todo el período, 2 por ciento, pero en 2011 cayeron a 1 por ciento.

Esto fue producto del cambio de modelo económico e inserción internacional argentino que afectó las pautas de cómo se habían desarrollado las vinculaciones argentino-chilenas desde los años 90. Argentina en ese entonces, producto del achicamiento de

13 Para los datos referidos al intercambio comercial argentino, tanto a sus monto como por su composición, véase: http://www.indec.gov.ar/ 
su economía, se había convertido en un exportador de energía, pero la reactivación de la última década lo volvió nuevamente en importador. Como lo señalamos oportunamente:

Ambos países tienen necesidades energéticas que sus mercados internos deben satisfacer $y$, pese a la complementariedad, es inevitable que existan dificultades y diferencias sobre las tarifas del gas que la Argentina le vende a Chile. Este conflicto se arrastra desde los recortes al envío de gas argentino decididos por el gobierno en 2004, durante el gobierno del presidente Ricardo Lagos. Se reavivaron en julio de 2006, cuando la crisis energética se hizo tan clara como la dependencia regional de lo que ocurra política y económicamente en Bolivia, pulmón gasífero del Cono Sur. Entonces, el gobierno decidió aumentar en un 45 por ciento el impuesto al gas que se vende a Chile, después de que Bolivia aumentara el precio del combustible que a su vez vende a la Argentina (Simonoff et al. 2007).

En general, los efectos en Sudamérica de la crisis de 2008 fueron más reducidos que en los países desarrollados, por su menor dependencia del comercio y las inversiones de estos, y una mayor relación con China e India. En el caso específico de la Argentina, además de ello, al tener la inversión extranjera una escasa influencia en el proceso de crecimiento, su reducción global no fue un problema inicialmente, lo que le permitió a la Presidenta decir en la Bolsa de Nueva York en 2008: "No necesitamos Plan B" (Fernández de Kirchner 2008). Aunque en la nueva década del milenio la necesidad de inversión externa para sostener el crecimiento se hizo más notoria, sumado al hecho de que la crisis no supuso hasta el momento, como inicialmente se creía y el gobierno argentino apostaba fuertemente a un cambio de paradigma económico a nivel global, esta situación complicó no solo el crecimiento, sino también los modos en los cuales la Argentina debe interactuar con el mundo.

Argentina con posterioridad a la crisis de 2001 desarrolló un perfil internacional en el cual privilegió dos planos: uno geográfico y otro conceptual. El primero es claramente conosureño, y de alineación con las naciones de la periferia; el otro es multilateral y de afirmación del derecho internacional.

Estos dos aspectos, la condición periférica y el multilateralismo, ayudan en muchos foros a la comprensión del problema de Malvinas, pero resultan insuficientes. Necesitamos que nuestro país involucre en su causa a otros jugadores relevantes del escenario internacional, como lo hizo oportunamente con Rusia o China, y que hoy se pueda extender a los BRICS (Brasil, Rusia, India, China y Sudáfrica). 
El rol chileno, más allá de la continuidad del apoyo en los reclamos argentinos desde 1990, resultó relevante para la firma de los acuerdos de 1999, sobre comunicaciones entre las islas y el continente, como asimismo en su apoyo, en diciembre de 2011, a la medida adoptada por el Mercosur de no permitir el arribo a sus puertos de naves con bandera de Malvinas, a pesar de los intentos de las autoridades británicas por revertirla.

\section{CONCLUSIONES}

Para concluir, creemos que a lo largo de estos 30 años, la política exterior argentina ha construido una estructura triangular en donde sus principales variantes son las relaciones con Washington y Brasilia.

El balanceo que realizó Argentina entre estos dos polos fue producto de las innovaciones ocurridas en el primer gobierno democrático: el giro realista hacia Estados Unidos y la política de cooperación hacia los vecinos, que permitieron buscar márgenes de maniobra en el escenario internacional.

Para nosotros, desde la restauración democrática y los cambios acaecidos desde fines de los 80 en el escenario internacional, las estrategias de las políticas exteriores tuvieron como marco la estabilidad de un régimen, dentro del cual se produce una conjunción de las pretensiones de autonomía e inserción que estaría caracterizando a un modelo reciente desde 1983.

Estas políticas exteriores se construyeron a partir de un interesante juego de equilibrios entre las tendencias autonomistas, que privilegiaron a la región como escenario principal de su agenda, y los de inserción restringida con la potencia hegemónica. Las diferencias entre estas tendencias estuvieron en la elección de su alianza principal. Mientras los primeros apuntaron a generar márgenes de maniobras en el sistema internacional sobre las alianzas con países con similares recursos y valores, los occidentalistas continuaron por una política de seguimiento hacia la potencia hegemónica.

Estos elementos nos permitieron delinear una presencia de cierta estructura triangular, donde el impacto de las tendencias autonomistas buscaron centrar su prioridad en Brasil, y las otras, las dependentistas, en Estados Unidos. De acuerdo a qué lado del triángulo se apoyó la estrategia principal de vinculación de Argentina con el mundo, fue el resultado obtenido. Existieron fuertes condicionantes, como el endeudamiento que generó la necesidad de acercarse a Washington para conseguir apoyo financiero, ya sea 
unilateralmente o a través de los organismos multilaterales que controla, lo que ocasionó una tensión en la búsqueda de un mayor marco autonómico. La primera opción también tuvo sus dificultades, ya sea por las transformaciones del sistema internacional, o los de Brasil, y que puede llevar hacia una "doble dependencia" (Figari 1997:195-96).

Salvo en el caso de Brasil, no existe otro país con el que se tenga tal grado de interacción e interrelación, de reuniones intergubernamentales en todos los niveles, como el que ocurre con Chile, siendo el caso más notable los avances en la integración de la defensa, incluso en un grado mayor que con nuestro principal socio.

El fracaso de la integración comercialista que llevaron adelante ambos países desde los 90 y que tuvo un revés con la crisis del gas desde comienzos de 2004, no debe ser vista como una calamidad. Podríamos decir que Argentina y Chile han ensayado una estrategia más profunda, sostenida por lo que José Morandé ha subrayado como una "constante histórica": la "búsqueda permanente de niveles mayores de autonomía y ejercicio de sus soberanías" que debe ser el núcleo de nuestra asociación (Morandé 2007:43).

Así lo han comprendido sus gobiernos y sus sociedades que, como dijera Raúl Bernal Meza, "es imprescindible el diseño de una 'agenda política' que, por cierto, debe tomar en consideración la política exterior y las relaciones regionales e internacionales de ambos países como su telón de fondo..." (Bernal Meza 2007:28).

Seguramente la conjugación de estrategias autonomistas, serán mucho más satisfactorias para ambos y que también la comprensión de nuestras diferencias requieren y requerirán de muchos desafíos, obstáculos y puestas a prueba que resultarán en una tarea que por desafiante, no deja de ser posible.

\section{REFERENCIAS}

1. Bernal Meza, Raúl. 2005. América Latina en el mundo. El pensamiento latinoamericano y la teoría de las relaciones internacionales. Buenos Aires: Grupo Editor Latinoamericano.

2—. 2007. "Política exterior regional y las relaciones con Argentina." Pp. 19-31 en Nuestros Vecinos, editado por M. Artaza y P. Milet. Santiago: RIL Editores.

3. Caputo, Dante. 1986. "Jornada Académica: 30 meses de Política Exterior Argentina. Disertación del Canciller..." Buenos Aires: Mimeo. 
4. Cavallo, Domingo. 2001. Pasión por crear. Buenos Aires: Planeta.

5. Cisneros, Andrés, comp. 1998. Política exterior argentina, 1989-1998. Historia de un éxito. Buenos Aires: Grupo Editor Latinoamericano.

6. Cisneros, Andrés y Escude, Carlos, ed. 1998. Historia General de las relaciones exteriores de la República Argentina. Buenos Aires: Grupo Editor Latinoamericano.

7. Escudé, Carlos. 1992. El realismo periférico. Fundamento para la nueva política exterior argentina. Buenos Aires: Planeta.

8_-2004. "A río revuelto. Autonomía periférica en un contexto de desorden global." Agenda Internacional. Visión desde el sur (I) 1:16-27.

9.— 2005. El Estado parasitario. Argentina, ciclos de vaciamiento, clase política delictiva y colapso de la política exterior. Buenos Aires: Lumiere.

10._ 2009. Realismo periférico: una filosofía de política exterior para estados débiles. Buenos Aires: Universidad del CEMA.

11.__ 2011. "La inserción de la Argentina en un mundo en cambio. China, una oportunidad histórica." La Nación, 26 de julio.

12. Fernández de Kirchner, Cristina E. 2008. "Disertación y respuestas de la presidenta Cristina Fernández en el Council of Foreing Relations (22/9/2008)." Consultado 12 de agosto 2012 (www.presidencia.gov.ar)

13. Ferrari, Gustavo. 1979. Esquema de política exterior argentina. Buenos Aires: Eudeba.

14. Figari, Guillermo. 1993. Pasado, presente y futuro de la política exterior argentina. Buenos Aires: Biblos.

15.—1997. De Alfonsín a Menem. Política exterior y globalización. Buenos Aires: Memphis.

16. 2004. "Los vaivenes de la Política Exterior Argentina: ¿Autonomía o dependencia?" Relaciones Internacionales 13 (26):99-117.

17. Fuentes, Oscar. 2007. “Chile y Argentina: una relación especial...” Pp. 51-67 en Nuestros Vecinos, editado por M. Artaza y P. Milet. Santiago: RIL Editores. 
18. Lacoste, Pablo. 2004. “Argentina y Chile, 1810-2000." Pp. 29-91 en Argentina y Chile y sus vecinos. Tomo I. Las relaciones bilaterales en el Cono Sur, editado por P. Lacoste. Córdoba: Caviar Bleu.

19. Lorenzini, María Elena. 2011. Política exterior, alianza estratégica y energía en América Latina. Las relaciones argentino-chilena bajo la lupa. Rosario: Homo Sapiens.

20. Morandé, José A. 2007. "Política exterior de Chile y Argentina: dos opciones contemporáneas de inserción regional." Pp. 33-50 en Nuestros Vecinos, editado por M. Artaza y P. Milet. Santiago: RIL Editores.

21. Paradiso, José. 1993. Debates y trayectoria de la política exterior argentina. Buenos Aires: Grupo Editor Latinoamericano.

22. Puig, Juan Carlos. 1980. Doctrinas internacionales y autonomía latinoamericana. Caracas: Universidad Simón Bolívar, Instituto de Altos Estudios de América Latina.

23.__ 1988. "Política Internacional Argentina." Pp. 19-45 en Argentina en el Mundo (19731987), editado por R. Perina y R. Russell. Buenos Aires: Grupo Editor Latinoamericano.

24. Rapoport, Mario. 1990. "Problemas y etapas en la historia de las relaciones internacionales de la Argentina.” Pp. 563-74 en Historiografía argentina (1958-1988). Una evaluación crítica de la producción histórica argentina, editado por Comité Internacional de Ciencias Históricas - Comité Argentino. Buenos Aires: CICH-CA.

25._ 2009. “Argentina: economía y política internacional. Los procesos históricos.” Diplomacia, Estrategia, Política 10:26-50.

26. Rapoport, Mario y Claudio Spiguel. 2003. "Modelos económicos, regímenes políticos y política exterior argentina." Pp. 169-235 en Foreign Policy and Political Regime, editado por J. Sombra Saraiva. Brasilia: Instituto Brasileño de Relaciones Internacionales.

27. Rodríguez, Jesús. 2011. El caso Chile. La Guerra Fría y la influencia argentina en la transición democrática. Buenos Aires: Capital Intelectual.

28. Russell, Roberto. 1994. Los ejes estructurantes de la política exterior argentina: apuntes para un debate. Serie Documentos e Informes de Investigación No 158. Buenos Aires: FLACSO.

29._ 2010. "La Argentina del segundo centenario: ficciones y realidades de la política exterior.” Pp. 227-307 en Argentina 1910-2010. Balance del siglo, editado por R. Russell. Buenos Aires: Taurus. 
30. Russell Roberto y Juan Gabriel Tokatlian. 2002. "El lugar del Brasil en la política exterior de la Argentina: La visión del otro.” Desarrollo Económico Revista de Ciencias Sociales 167 (42): 405-28.

31.__ 2003. El lugar de Brasil en la política exterior argentina. Buenos Aires: Fondo de Cultura Económica.

32. Simonoff, Alejandro. 1999. Apuntes sobre las politicas exteriores argentinas. Los giros copernicanos y sus tendencias profundas. La Plata: IRI.

33. _ 2003. "La interpretación del pasado como eje de la disputa de la política exterior actual: de Puig a Escudé." Relaciones Internacionales 25 (12):129-48.

34. 2012. Teorías en movimiento. Los orígenes disciplinares de la política exterior y sus interpretaciones históricas. Rosario: Prohistoria Ediciones.

35. Simonoff, Alejandro et al. 2007. "Séptimo Informe Semestral sobre Política Exterior del gobierno de argentino (Septiembre 2006 - marzo 2007).” Relaciones Internacionales. Sección Digital 32 (16).

36. _ 2010 "Décimo Tercer Informe Semestral sobre Política Exterior del gobierno argentino (Septiembre 2009-marzo 2010).” Relaciones Internacionales. Sección Digital 38 (19). 